\title{
Don't ask for ideas and innovations, ask for what they do Understanding, recognizing and enhancing (women's) innovation activities in the public sector
}

\author{
Anna Isaksson ${ }^{1 *}$ Camilla Andersson ${ }^{2}$, Emma Börjesson ${ }^{3}$
}

\begin{abstract}
This article demonstrates how the innovation capacity in the public sector, such as in elderly care, can be recognized and enhanced if the daily experiences of the employees, i.e. what women are doing in their everyday work, are taken into account. Women working in elderly care encounter a number of challenges and have different strategies for solving them in order to provide good care for the elderly. These solutions are often nontechnical and non-digital and, therefore, not regarded as "good ideas" and innovations. Asking for "ideas" and "potential innovations" prevents the staff from identifying these innovative solutions since they regard them as nothing special. However, when the point of departure is taken in everyday experiences, it is possible to challenge the male-dominated discourse on innovation and capture innovations. Consequently, this article suggests that innovation activities and innovation models in for instance the public sector should address and be grounded in experiences rather than "ideas".
\end{abstract}

Keywords: Innovation; ideas, gender; experiences; elderly care; public sector,

Submitted: March $18^{\text {th }}, 2020$ / Approved: August $21^{\text {st }}, 2020$

\section{Introduction}

Researchers of gender and innovation have in the last decades demonstrated how the concepts innovation and innovators are gendered and, thus, promote men and masculinity as the norms for innovation activities (cf. Nählinder, Tillmar \& Wigren 2015; Lindberg, 2010; Nyberg, 2009; Pettersson, 2007; Blake and Hanson, 2005). In this article, we demonstrate how the innovation capacity in the public sector, in this case in elderly care, can be visualized, enhanced, and broadened if we take our point of departure in the daily experiences of the employees, i.e. in what mainly women are doing in their everyday work. The article contributes valuable knowledge on how women can be given a voice in innovation processes on their own conditions, i.e. not by fitting into innovation concepts and ideas originated from the male-dominated private, technological, and product-driven sector (cf. Utbult 2007; Blake and Hanson 2005). This is important for the development in the elderly care sector as well as from an overall gender equality perspective since it concerns how to work with development and innovation in the public sector and other occupations where women are in the majority. The aim of the article is to problematize the dominant idea(s) of innovation and suggest alternative pathways for capturing innovative ideas, solutions or potential innovations that might be hidden or neglected in the male-dominated discourse on innovation. In doing so the article addresses the following research questions:

- How do women working in elderly care describe their everyday work?

- What are recognized as challenges and how do they solve these challenges?

- What can we learn from these experiences and stories when it comes to enhancing development and innovation in the public sector or in any other female-dominated sector?
The article is organized as follows: We will first place this article in its context. During 2017-2018 a collaborative project between [will be inserted after review], and two municipalities was conducted. This project will be described before we present a selection of previous studies on gender and innovation that is of special relevance for this article. Following that we will present our theoretical approach. We are inspired by institutional ethnography as, for example, Smith (1987; 2005a; 2005b) practices it. After this we will discuss our methodological framework and then our empirical findings that derive from observations at residential homes as well as interviews with women working in the elderly care sector. Finally, in our concluding remarks, we will discuss the implications of our study.

\section{Context of the study and project}

During 2017 and 2018 we, researchers at [will be inserted after review], carried out a collaborative project with the [will be inserted after review] and two municipalities. Taking a gender and equality perspective as the point of departure, the overall aim of the project was to find ways to stimulate innovation in elderly care. The project process started with observations at several residential homes. Interviews with home care staff and staff at residential homes were also conducted. Initially, and into the first part of the project, we were interested in collecting stories about how the staff perceived gender equality barriers in their work and if they had any ideas about how these could be broken down and overcome in an innovative way. However, the project aim and the research questions came to be reformulated during the project process in dialogue with all the project partners. This was crucial for the results of the project and we will get back to this when we present our empirical data.

(1) School of Education, Humanities and Social Sciences, Halmstad University, Sweden.

(2) Department of Design, Aalto University, Aalto, Finland.

(3) School of Information Technology, Halmstad University, Sweden.

*Corresponding author: Anna.isaksson@hh.se 


\section{Previous research: Gender and innovation}

According to Pecis (2016) little attention has been paid to exploring the combination of gender and innovation. Innovation literature tends to be gender blind (Le Loarne \& Gnan 2015). However, there is a growing body of research that has made important contributions to this field. Aspects of gender in innovation have been examined in multiple contexts, for example at policy level, in entrepreneurial businesses, public organizations and design (e.g. Alsos et al., 2016; 2013; Pettersson \& Lindberg 2013; Andersson et al., 2012; Danilda \& Thorslund 2011; Ranga \& Etzkowitz, 2010). Research has demonstrated that women are not perceived as innovators and, therefore, their ideas are not heard. However, it has been argued that it is not women who lack innovation capability, rather it is the organizational practices and structures that counteract women's innovative behavior (Alsos et al 2013; Cooper 2012). Another issue that has been addressed concerns the dominant images of innovation and innovators. These images build on stereotypical notions of gender and are characterized by a masculine norm. Andersson et al (2012) discuss how we seldom consider an ethnic minority woman with an idea on how a process may contribute to social justice as an innovator with an innovation. Notions of innovation and innovator are linked to a man with an idea on how a product can have an impact in a traditional industry.

Other studies have problematized a gender bias in recipients of research grants as well as a gender bias in public bodies that support innovation. Public support for innovation is, in general, provided by men and given to men (c.f. Lindberg, 2009; Viner et al 2004). These kinds of studies also confirm that the dominant notion about innovation is gendered and that women do not fit the prevalent ideas about innovation. Thus, women are accused of being less innovative than men. However, Foss et al (2013) show that women are equally innovative as men when it comes to generating new ideas, but women's ideas tend not to be implemented in the organization. A lack of collegial support might be a partial explanation for this.

Some researchers argue that a more equal innovation climate is not just about including more women in innovation activities and processes. To counteract the gendered constructions of innovation one must interpret and understand innovation in new and different ways (Wikhamn and Knights 2013). Current definitions are to a great extent considered gender neutral. However, as Pettersson and Lindberg (2013) demonstrate, innovation is strongly linked to masculine connotations and masculinity. Wikhamn and Knights (2013) also discuss how innovation tends to be conceptualized as technology and products. Consequently, this limits the ways in which innovation activities can take place and what are and are not regarded as innovations.

Even if valuable research contributions have been made, there are still some knowledge gaps in the area of gender and innovation (Alsos et al 2016). Foss and Henry (2016) have reviewed literature on gender and innovation and found that few articles really discuss the relationship between gender and innovation, whereas the literature on gender and entrepreneurship is more developed and advanced. Con- sequently, there is a need for more innovation studies that include a gender perspective. They argue that the field of innovation would especially benefit from increasing the number of studies that are grounded in feminist epistemology. Moreover, innovation research needs to explore methods that can highlight the situated knowledge of innovation. According to Alsos et al (2013) future research should also problematize the connection between technology and innovation and explore innovation activity in service sectors, for example. Nählinder et al (2015) claim that previous studies on innovation have primarily focused on male-dominated industries and manufacturing sectors. Little attention has been given to innovation studies in public and service sectors. A consequence of this is that men and male-dominated sectors are portrayed as being more innovative than women and female-dominated sectors. To avoid this bias, it is important to conduct more innovation studies in female-dominated sectors (Nählinder et al 2015; Ljunggren et al 2010).

An important contribution concerning a female-dominated sector is Nählinder's (2010) paper on nurses as innovators in the public sector. Nählinder discusses how female nurses are often not seen as innovative and few efforts and innovation policies seem to concern them. Nurses and other care workers solve problems on a daily basis, but these solutions are not described in terms of innovation. Problemsolving in this sector is taken for granted and since it is not assumed to be synonymous with technology, the connection to innovation is not made. As a result, innovations in the care sector are invisibilised because they are considered non-innovations. However, in her presentation of a joint project concerning the care sector, Nählinder presents a number of innovations this project resulted in, including:

(...) the pyjamas for incontinent dementia patients, which prevents them from removing the diaper, the catheter underpants, which facilitates the choice of medical lotions, the skirt-peg, which facilitates assisted toilet visits for patients with skirts. The innovations emerged so far have three common aspects: (i) they are not technologically advanced, (ii) they are everyday innovations, and (iii) they are product innovations, despite the fact that the idea carriers are service providers (Nählinder 2010:18).

This article addresses some of the knowledge gaps presented above. As Foss \& Henry (2016) argue, there is a need for more studies grounded in feminist epistemology. Consequently, our study with its theoretical approach, i.e. institutional ethnography, attempts to go some way toward filling this need. Further, this article explores and questions the connections between technology and innovation through demonstrating what consequences these connections have for innovation activities, especially within the female-dominated elderly care. In doing so it also addresses how to recognize and take care of the actual innovation activity and capacity in a (femaledominated) service sector. As mentioned earlier, previous research (e.g. Alsos et al, 2013; Nählinder et al 2015) has demonstrated that there is a need for more studies concerning the service sector, which seems to be neglected in innovation studies and, therefore, is understood as un-innovative. 


\section{Theoretical framework: Institutional Ethnography}

Smith (2005a) argues that institutional ethnography aims to illustrate society's relations of power and inequality, in which people participate by doing what they do in their everyday lives. Furthermore, Smith (1987) claims that what people do, say, think and write is interwoven with what she describes as "ruling relations". According to Smith, the development of capitalism is an important explanation for the development of society's ruling relations. Through this societal development, women were strongly associated with the private sphere and, thus, silenced and excluded from politics, the market and the public sector. This resulted in women being almost absent in the creation of the thoughts, images, and symbols through which society can be seen and understood. Hence, women have been forced to understand their world through concepts and beliefs that they themselves have not been allowed to define (Smith 1974; 1987). The ruling relations are mediated and reproduced in and through the media, the state, organizations, administration, and management. These relations are also expressed in and through scientific, technical, political, and cultural discourses. Consequently, these discourses affect and regulate people's lives (DeVault 2006; Smith 2005b). A discourse can be understood as something more than statements. It refers to trans-local relations coordinating the practices of people in particular places at particular times (Smith 2005a). In relation to the theme of this article, a prominent discourse in media, politics, and science could be described in terms of "the large and growing older population". What characterizes this discourse are descriptions of today's challenges in the elderly care sector. In, for example, Official Reports of the Swedish Government (see for instance SOU 2017:21) we can read about the rapidly growing population and that the health and elderly care sector faces many challenges. These challenges include increased chronic diseases among the elderly, fewer working-age people and a labor shortage. The core of the discourse is that new welfare technology and digital products are formulated as necessary solutions to provide care for older people in new and innovative ways and to counteract poorer quality in the welfare sector.

In order to understand how the ruling relations operate, the point of departure must be taken in people's everyday lives and in the discourses that affect people's actions and interactions (Smith, 1987). People are often unaware of the relationships that govern their thoughts, decisions and actions. Thus, people can also unconsciously participate in the ruling relationships and reproduce different forms of power and inequality (Weight 2006; Campbell and Gregor 2004).

Applying an institutional ethnography perspective has, in this article, meant that it is the women's everyday experiences and stories about the challenges they see in their daily work of caring for the elderly and how they solve these that are in focus. Of particular interest is to understand and interpret these stories as part of society's ruling relations and, thus, as part of the dominant notions of what innovation "is" and who is supposed to be the carrier of ideas. Furthermore, as mentioned above, today's descriptions of elderly care's challenges, solutions, and future are often described in terms of the need for welfare technology and digitization. This discourse has considerable consequences, which will be addressed later in the article.

\section{Methodological framework}

As mentioned above, we conducted observations and interviews during the project period. Observations were made at four residential homes in Sweden. During a six-month period, we visited each residential home on two to three occasions. Each occasion lasted for four to eight hours. Inspired by Cranz (2016) our observations were inspired by behavioral observations. This means that the researcher focuses on studying what people do (which is also emphasized in institutional ethnography) in a specific context, in our case at residential homes. How people use the environment is also of great interest for the researcher. During our observations we identified a range of challenges that the staff face in their everyday work. We could also see how they solve a number of problems in what our research group considered innovative ways, although initially, as we have already mentioned, the staff themselves didn't recognize these actions as innovative solutions. In fact, they didn't recognize it as "anything special" at all. During our observations we had the opportunity to talk with the elderly care staff. Methodologically this could be described as a more casual conversation, i.e. what Pink (2011) refers to as "walking and talking". We combined these observations and conversations, which allowed us to uncover the meaning of the activities and behaviors, with more formalized interviews with both home care staff and elderly care staff. This article is based on ten interviews. These interviews were organized as semi-structured interviews, i.e. an open interview, allowing the interviewees to suggest new ideas and perspectives during the interview (cf. Galletta, 2013). In the observation phase, which also included "walking and talking", we discovered that our approach and questions limited the interviewees' responses and that we had to redefine our interview questions. Therefore, we came to develop a framework of few but broad interview themes: "A 'normal' day at work", "Challenges" and "Strategies for handling challenges".

Our methodological approach harmonizes with our theoretical framework. In institutional ethnography there is an interest in finding out what discourses the interviewees are relating to in their actions and speech, as discourses are considered a mediator for social and ruling relations. However, as women (people) are seen as actors, the most interesting thing to capture is what people do with the discourses (cf. Campbell, 2006). When analyzing the empirical data some questions have therefore been guiding in the categorization process of the material: What discourses are present in the interviewees' stories? How do these discourses affect their experiences and stories? When we here refer to "empirical data" this includes all the data collected in the project, i.e. also the data collected before we changed our approach and research questions.

\section{Results}

\section{To capture or be captured in the dominant innovation discourse}

As mentioned earlier, it was difficult to capture innovation ideas among the staff members when we asked for ideas and innovations. Some respondents claimed that they could not see that they did anything special or innovative. Some just said "I just do my work; it is nothing special at all". However, during our observations, we 
noticed that the staff worked with what could be regarded as innovative solutions every day. After conducting a number of interviews and observations, we asked ourselves why we had organized our interviews in the way we had and what we could change in our research approach. By reminding ourselves what Smith (1987) points out, i.e. what people do, say, think, and write is interwoven with the ruling relations - we realized that our interview questions actually reflected how captured we ourselves were by the discourse associated with the traditional and dominant view on innovation. As presented above, previous research has demonstrated gendered constructions of innovation and the importance of broadening the interpretations and understandings of innovation. Innovation tends to be conceptualized as technology and products (Wikhamn and Knights 2013) and there is a strong connection between innovation and masculinity (Pettersson and Lindberg 2013). As researchers, we did what is normally done in innovation processes. We were actually reproducing rather traditional notions of innovations, i.e. searching for "promising ideas" and replicating the notion that (...) ideas are the starting point for innovation (c.f. van den Ende et al, 2014). However, from previous studies we know that women seldom view themselves as innovators and idea generators. Hence, their answers could be considered to be somewhat expected. The women's solutions in their everyday work are seldom technological, and as innovation has technological connotations this probably also affects their perception of themselves as not being innovative. Earlier we described what we perceive as a dominant discourse in relation to health care and elderly care, i.e. the growing and older population demanding new technologies and digital products. Therefore, when non-technological solutions are developed and adopted, they are not considered to be innovations. We have two intersecting discourses - the male and technological discourse on innovation and the other, growing discourse claiming that the challenge with the older population requires welfare technology and digital products.

To summarize, in the beginning of the project it is now obvious that we as researchers and our respondents unconsciously participated in the ruling relationships (cf. Campbell and Gregor 2004; Weight 2006) as we reproduced the male-influenced dominant ideas about innovation and the dominant idea concerning the challenges within elderly care. We asked questions that did not consider the respondents' situated perceptions and knowledge of innovation. They answered as Smith (1974; 1987) expresses it: through concepts and thoughts they have not been allowed to define. As their solutions do not fit the dominating technically oriented discourses and expectations on "real" innovations, they just believe they do not have any innovative ideas. Consequently, we were all caught in the dominant ideas on innovation.

So, what happened when we changed strategy and the way we asked questions? Instead of using terms such as "innovation" and "ideas" we simply asked them to describe a "normal" day at work and what challenges they faced when taking care of the elderly and what solutions they developed and implemented in their everyday work. Inspired by institutional ethnography as practiced by Smith (1987; 2005a), we took our point of departure in the everyday lives of the respondents. We gathered several examples of challenges and solutions in the elderly care sector, some of which are presented below.

\section{Innovative non-technical solutions}

\section{The towel over the toilet seat}

Many of the respondents mentioned that visits to the toilet are a major daily challenge. Due to changes in their cognitive abilities, many elderly people, especially those with dementia, experience great discomfort when going to the bathroom. The toilet can be perceived as a large hole and many elderly people, therefore, refuse to go to the toilet. The women working in elderly care stated that it does not feel good to force someone to sit on the toilet seat, although it is of course necessary. One woman described how she and some colleagues used to solve this by putting a towel over the open toilet seat. When the elderly woman or man stood with their back to the toilet and was about to sit down, the staff pulled away the towel. In this way, the elderly person could sit down without fear of being thrown down a large hole and at the same time the staff did not have to "force" the elderly person to sit down on the toilet.

\section{The carpet like a bridge on the floor}

As in the example above, many elderly people with dementia experience discomfort when walking across a surface of floor that changes color. For example, if the floor starts out light, then changes to dark, then light again, many elderly may experience this change in color as a large hole in the floor. Some staff members said that it may, therefore, be difficult for the elderly to cross certain areas of a building and that they may either have to be lifted over the dark area or be convinced that it is not a hole. A solution that some women described was to put a carpet over the dark area. The carpet is then interpreted as a "bridge" and it becomes harmless to walk across the darker part of the floor. While this solution can effectively make the elderly feel safe, it also poses a risk as carpet edges can make it easier to stumble.

\section{Song to calm anxiety}

Occasionally, the home care staff feels that older people (often with dementia) are anxious. A woman working in home care discovered that one way to calm an older woman's concerns was to sing. When the care worker began to sing a special song, she noticed that the older woman suddenly began to join in and that the anxiety disappeared. So every time the older woman seems anxious, they usually sing this song together. The care worker's interpretation was that the older woman probably had a special relationship to this particular song. The song made it possible for the home care staff to carry out their work tasks, administer medicine and help the older woman with visits to the toilet.

\section{The elevator - a challenge with multidimensional solutions}

During our interviews and observations, the elevator (at the community center for the elderly) appeared to be one of the biggest challenges to deal with in everyday life. The staff stated that they are not allowed to lock the elderly in, but if the elderly use the elevator by themselves to move to another floor or out of the building, this is usually associated with a number of risks. In various ways the staff, therefore, try to prevent the elderly from using the elevator. Some residential home centers have solved it by placing curtains in front of the elevator or covering the elevator doors with wallpaper similar to a bookcase. Many elderly people (for example with dementia) do not, 
therefore, perceive it as an elevator. A woman working at a center for the elderly explained how to put tape over the sensors of the elevator doors. In this way, you can keep the elevator doors open and "park the elevator" on one floor (for example, on the elderly people's basement floor). This, however, prevents anyone else from using the elevator in the meantime. At another residential home, bells have been placed on the elevator doors so that the staff hears if the doors are opened. As staff, you do not then have to "follow" and "monitor" the elderly as they walk around the corridor from fear that they will take the elevator. If the elevator doors open, the staff hears it and can quickly go there to see what is happening.

\section{Fictional stop and clients}

Home care staff visit the elderly in their homes according to a certain schedule. Each visit is expected to take a certain amount of time - if the visit takes more or less than the expected time, this is considered a deviation. Some women working in the home care service told us that the municipality they work in had purchased a system that had been developed in the logistics and transport sector. The purpose of this system was to enable the home care service to better plan and optimize travel between the elderly. However, since the system was basically created for vehicles such as trucks, it did not take into account that travel time for the home care staff may vary depending upon the direction of travel. This is because the home care staff usually cycle or walk between their clients, which means that one way - if it is hilly, for example - can take longer than traveling in the opposite direction. To solve this, the staff has put in fictitious clients, i.e. stops on the road that do not exist in reality. This is done only in order to create the correct travel time in the system.

\section{The toilet sign on the inside of the front door}

A woman in home care service recounted how an elderly woman with dementia had often left her apartment and gotten lost in the neighborhoods around her home when the home care staff came to carry out their work. The woman, who had years of experience working in the home care service described how she once put up a hand-drawn picture on the front door with a classic symbol for the men's toilet. The older woman knew very well that as a woman, she did not go into the men's toilet and, therefore, she stayed inside the apartment so the staff could carry out the work (such as administering medication, dressing and showering the client) that they were there to do. Most importantly, the older woman did not leave her home and risk injuring herself or getting lost.

\section{Discussion}

Each example above illustrates creative solutions to the various challenges that restrict the staff in carrying out their work tasks. However, the women tend not to consider their solutions as innovations since there is a discrepancy between their solutions and what is regarded as "real" innovations. This could, as mentioned earlier, be understood as a natural consequence of the strong link between the concept innovation and masculine connotations and masculinity (Pettersson and Lindberg 2013), and that innovation to a great extent is conceptualized as technology and products (Wikhamn and Knights 2013). Further, according to the dominant discourses on the challenges in the elderly care sector, there is probably a strong belief that suggested solutions and innovations should be technical and digital. During our interviews it was also obvious that as they do not regard their solutions as "something special" and since their solutions do not fit the traditional notions of innovations, there is no dissemination of "best practices". Consequently, several innovative solutions and ideas are stuck in a single workplace and among a few employees. Our findings have several similarities with Nählinder's (2010) study. She argues that nurses and other care workers solve problems on a daily basis, but their solutions are not considered as innovations. In her study, Nählinder illustrates some examples of innovations in the care sector and concludes that they have three common aspects: (...) (i) they are not technologically advanced, (ii) they are everyday innovations, and (iii) they are product innovations, despite the fact that the idea carriers are service providers (Nählinder 2010:18).

Some might argue that the solutions found in Nählinder's (2010) study and our study are too "simple" to be regarded as innovations. However, as previous research has demonstrated - innovation must be interpreted and understood in new and different ways (Wickhamn \& Knights, 2013) if we seriously want to challenge the gender-biased definitions of innovation. Let us delve into one of the examples above - the towel over the toilet seat - to illustrate how the image of innovation could be challenged through the experiences and stories of the women. The solution with the towel over the toilet seat makes it more comfortable for some older persons and it also makes it easier for the staff to perform their tasks. So why is it not talked about and perceived as an innovation?

Firstly, when does something become an innovation? Could the original idea in this case, i.e. a towel over the toilet seat (Figure 1) be regarded as an innovation? Or do we have to make it more "productified" first? What happens if the towel is folded in special ways (Figure 2), or if we make disposable products (Figure 3) of it? Or do we need to add some mechanics, such as a mechanical crank (Figure 4), for it to be considered an innovation? What if, instead of a towel, we make it a built-in function in the toilet seat that can be folded in and out automatically (Figure 5) - is that an innovation? Or do we have to fully automate it and make the function high-tech (Figure 6) for us to talk about it as an innovation? Below we demonstrate all of these solutions in some simple sketches.

Figure 1: Original idea: a towel over the toilet seat

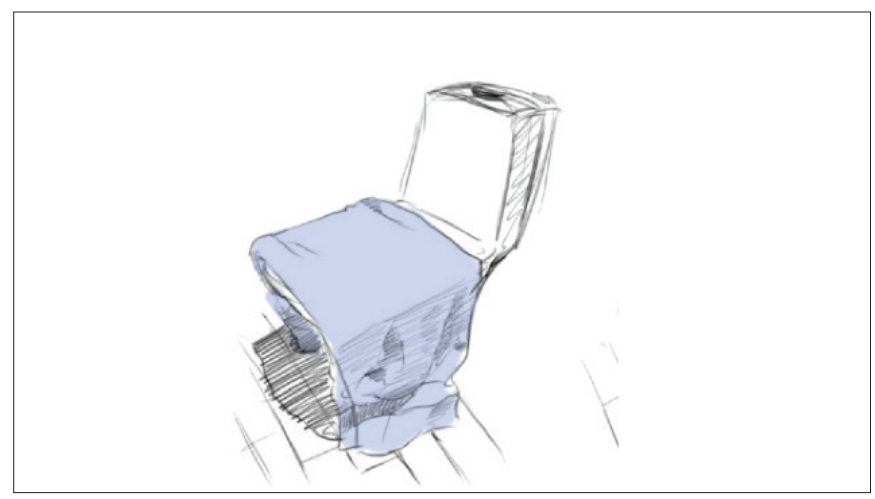


Figure 2: Folded towel

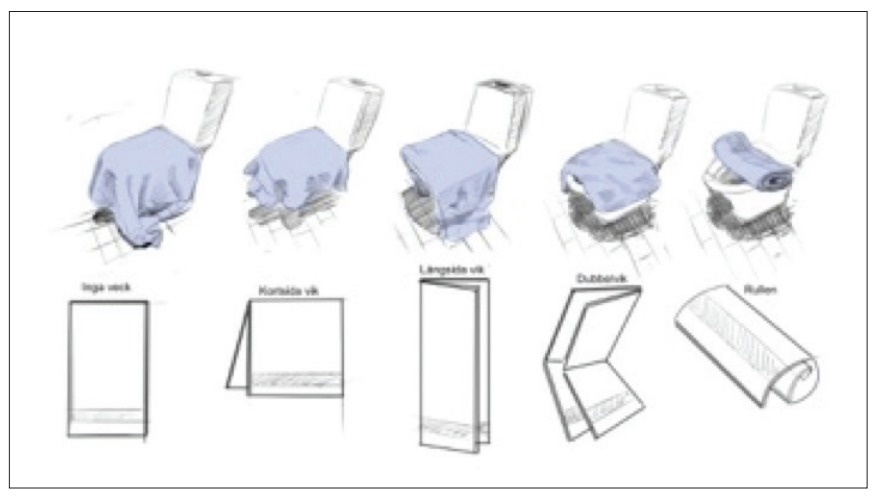

Figure 3: The towel as a disposable product

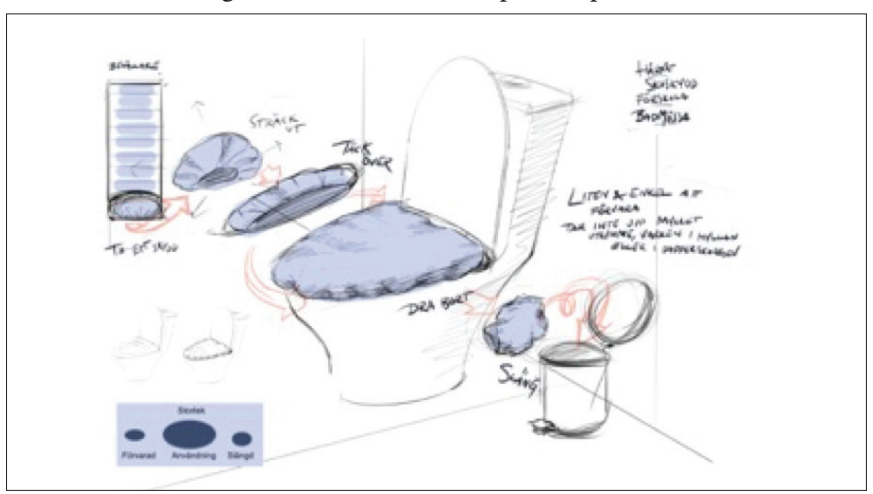

Figure 4: The towel with a mechanical crank

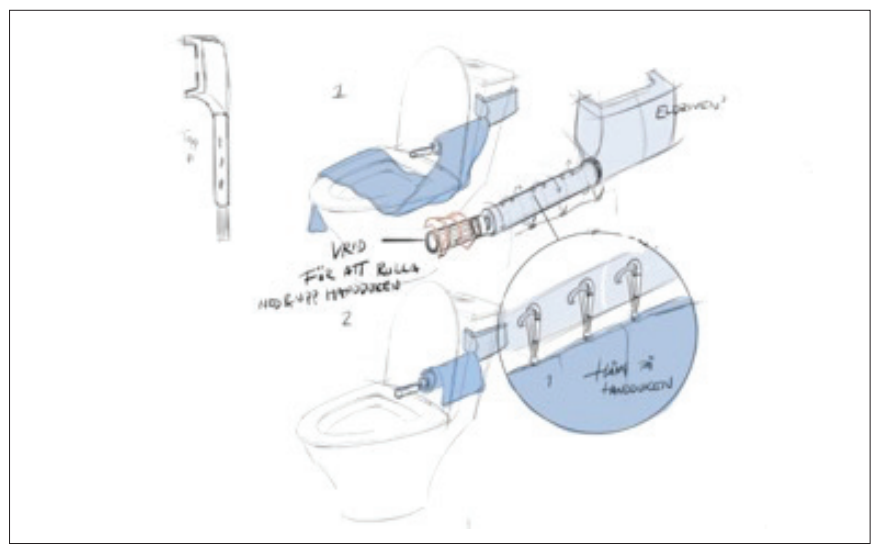

Figure 5: Built in function instead of towel

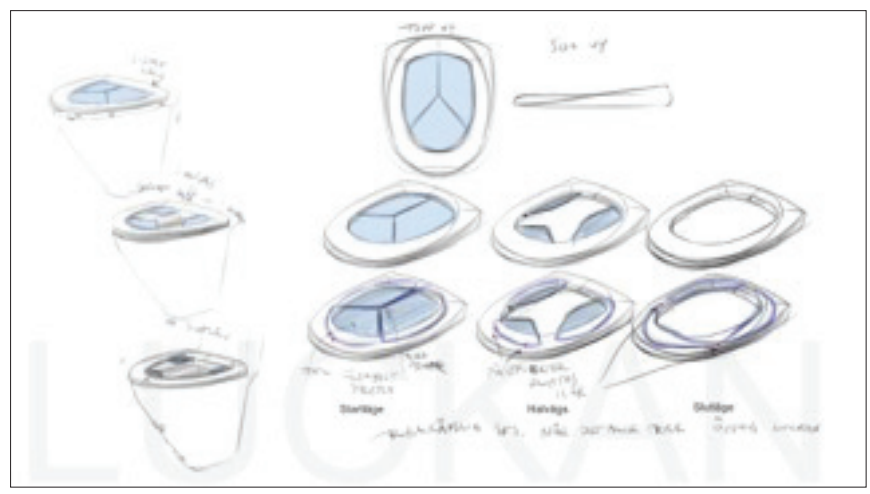

Figure 6: High-tech toilet with a number of functions

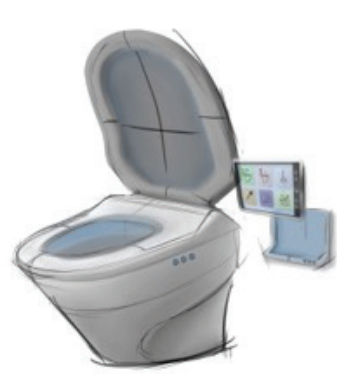

Since there is a strong connection between innovation and technology (Utbult 2007; Blake and Hanson 2005) we argue that there are systems and policies today that encourage and "take care" of the kind of ideas that are represented in figure 5-6. However, ideas like those in figure 1-4 are less encouraged even though they solve a problem and might be more cost-effective than those in the right-hand fields. As a consequence, ideas in the left-hand fields are neither seen as potential innovations nor disseminated as they are not regarded as important or valuable. They do not match the dominant discourse. Thus, we miss the innovation capacity and innovative solutions that result in good care for the elderly. The dominant discourse associated with the ageing population and the demand for goods and services are strongly associated with the conceptions of the need for technical and digital solutions. As we have discussed several times, this might also be a reason for why the women in elderly care do not talk and think about their daily solutions as innovations; even if they actually solve problems in their everyday work.

In this article we have addressed three questions: How do women working in elderly care describe their everyday work? What are the challenges and how do they solve these challenges? What can we learn from these stories and experiences when it comes to enhancing innovation in this female-dominated sector? As we have demonstrated through our empirical findings, the women working in elderly care encounter a number of challenges and they have different strategies for solving them in order to provide good care for the elderly. These solutions are generally non-technical and nondigital and, therefore, not regarded as "good ideas" and potential innovations by the women. We were able to capture these solutions by reformulating the research questions we had when we first started to interview the employees. Asking for ideas and thoughts about potential innovations - as we did in the beginning of the project - prevented both the staff and us from identifying these innovative solutions. We participated in the dominant discourse on innovation and how innovation should be enhanced in the elderly care sector, reproducing the ruling relations (cf. Smith 2005a). When we reformulated our question and, in accordance with what Smith (1987) suggests, took our point of departure in the everyday experiences and asked what the women were doing in their everyday work, it was possible to capture possible innovations. 
We have captured innovations or possible innovations in the sense of solutions that make their everyday work possible, and solutions that take the well-being of older persons into account. What we can learn from these stories and experiences when it comes to enhancing innovation is that work with innovation and development in a female-dominated sector such as elderly care, should start in a broad definition of innovation and in everyday experiences. Not as in several innovation theories and innovation models today - in idea-generating processes and idea capturing. This article indicates that if we recognize everyday lives and experiences as important sources for innovation activities and innovation models, we could also identify solutions and everyday innovations that are non-technical or not technologically advanced. These solutions and ideas could possibly be developed into technical solutions if suitable, but the most important thing is that we acknowledge them as important solutions, innovations or potential innovations. Otherwise they will not be recognized and disseminated. This is certainly a waste of women's experiences, work and ideas. It will result in missed innovation opportunities in the service sector and most importantly, it prevents the staff sharing their thoughts on how to provide good care for the elderly.

\section{References}

Alsos, GA., Ljunggren, E. \& Hytti, U. (Eds.). (2016). Research Handbook on Gender and Innovation. Edward Elgar Publishing Ltd.

Alsos, GA., Ljunggren, E. \& Hytti, U. (2013). Gender and innovation: State of the art and a research agenda. International Journal of Gender and Entrepreneurship 5(3): 236-256.

Andersson, S., Berglund, K., Gunnarsson, E. \& Sundin, E. (Eds.). (2012). Promoting Innovation. Policies, Practices and Procedure. Stockholm: Vinnova-Verket för Innovationssystem/ Swedish Governmental Agency for Innovation System.

Blake, M.K. \& Hanson, S. (2005). Rethinking innovation: context and gender. Environment and Planning A. Vol. 37 No. 4, pp. 681-701.

Galletta, A. (2013). Mastering the Semi-Structured Interview and Beyond. From research design to analysis and publication. New York University Press.

Campbell, M L. (2006). "Institutional Ethnography and Experience as Data”. In D. Smith (Ed.) Institutional Ethnography as Practice. Lanham: Rowman \& Littlefield Publishers, Inc.

Campbell, M. \& Gregor, F. (2004). Mapping Social Relations. A Primer in Doing Institutional Ethnography. Rowman/Littlefield.

Cooper, R. (2012). The gender gap in union leadership in Australia: a qualitative study. Journal of Industrial Relations. Vol. 54 No. 2, pp. 131-146.

Cranz, G. (2016). Ethnography for Designers. London: Routledge.

Danilda, I. \& Thorslund, JG. (Eds.). (2011). Innovation and Gender. Stockholm: Vinnova-Verket för Innovationssystem/Swedish Governmental Agency for Innovation System.
DeVault, M L. (2006). Introduction: What is Institutional Ethnography? Social Problems vol. 53, nr. 3 (294-298).

Foss, L., Henry, C. (2016). "Doing gender in innovation: A thematic review and critique of the literature". In G A. Alsos., U. Hytti \& E, Ljunggren (Eds.). Research Handbook on Gender and Innovation (pp. $17-48)$

Foss, L., Woll, K. and Moilanen, M. (2013). Creativity and implementations of new ideas: do organisational structure, work environment and gender matter? International Journal of Gender and Entrepreneurship, Vol. 5 No. 3.

Le Loarne, S. \& Gnan. L. (2015). Introduction to the special issue: Is innovation gendered? International Journal of Entrepreneurship and Small Business 24(1): 1-3.

Lindberg, M. (2010). Samverkansnätverk för innovation: en interaktiv och genusvetenskaplig utmaning av innovationspolitik och innovationsforskning. Dissertation, Luleå University of Technology, Luleå.

Lindberg, M. (2009). Män och manlighet i Sveriges innovationspolitik, Tidskrift för genusvetenskap, nr. 2-3: 29-43.

Ljunggren, E., Alsos, G., Amble, N., Ervik, R., Kvidal, T. \& Wiik, R. (2010). Gender and Innovation: Learning from Regional VRI-projects. NF-report 2/2010, Nordland Research Institute, Bodö.

Nyberg, A.C. (2009). Making ideas matter: gender, technology and women's invention. Dissertation, Department of Human Work Sciences Division of Gender and Innovation, Luleå University, Lulea.

Nählinder, J., Tillmar M. \& Wigren, C. (2015). Towards a genderaware understanding of innovation: a three-dimensional route. International Journal of Gender and Entrepreneurship. Vol. 7 No. 1, pp. 66-86.

Nählinder, J. \& Sundin, E. (2009). Everyday innovation in elderly care and healthcare. M. Döös \& L.

Wilhelmson (Eds.) Organising Work for Innovation and Growth. Experiences and efforts in ten companies. Series: VINNOVA Report VR 2009:22

Pecis, L. (2016). Doing and undoing gender in innovation: Femininities and masculinities in innovation processes. human relations. Vol. 69(11) 2117-2140.

Pettersson, K. (2007). Men and male as the norm? A gender perspective on innovation policies in Denmark, Finland and Sweden. Report 4, Nordregio.

Pettersson, K. \& Lindberg, M. (2013). Paradoxical spaces of feminist resistance: Mapping the margin to the masculinist innovation discourse. International Journal of Gender and Entrepreneurship 5(3): 323-341. 
Pink, S. (2011). Multimodality, multisensoriality and ethnographic knowing: Social semiotics and the phenomenology of perception. Qualitative Research 11(3): 261-276.

Ranga, M. \& Etzkowitz, H. (2010). Athena in the world of Techne: The gender dimension of technology, innovation and entrepreneurship. Journal of Technology Management \& Innovation 5(1): 1-12.

SOU 2017:21. Läs mig! Nationell kvalitetsplan för vård och omsorg om äldre personer.

Smith, D E. (1974). Women's Perspective as a Radical Critique of Sociology. Sociological Inquiry vol. 44, nr. 1 (7-13).

Smith, D E. (1987). The Everyday World as Problematic - A Feminist Sociology. Boston: Northeastern university Press.

Smith, D E. (2005a). Institutional Ethnograpy. A Sociology for People. Walnut Creek, CA: AltaMira Press.

Smith, D E. (2005b). Texts, Facts and Femininity. Exploring the Relations of Ruling. London: Routledge.
Utbult, M. (2007). Måste innovationer vara av metall? Att tänka om och skapa nytt i kommuner, landsting och regioner. SKL, Trygghetsfonden, Vinnova, Stockholm.

van den Ende, J., Frederiksen, L. \& Prencipe, A. (2014). The Front End of Innovation: Organizing Search for Ideas. The Journal of Product Innovation Management. Vol 32, Issue 4, pp 482-487.

Viner, N., Powell, P. and Green, R. (2004). Institutionalized biases in the award of research grants: a preliminary analysis revisiting the principle of accumulative advantage. Research Policy, Vol. 33 No. 3, pp. 443-454.

Weight, J. (2006). Compromises to Carework: The Social Organization of Mothers' experiences in the Low-Wage Labor Market after Welfare Reform. San Marcos Social Problems vol. 53, nr. 3 (332-351).

Wikhamn, B.R. \& Knights, D. (2013). Open innovation, gender and the infiltration of masculine discourses. International Journal of Gender and Entrepreneurship, Vol. 5 No. 3. 